\title{
An Unusual Presentation: Renal Tuberculosis
}
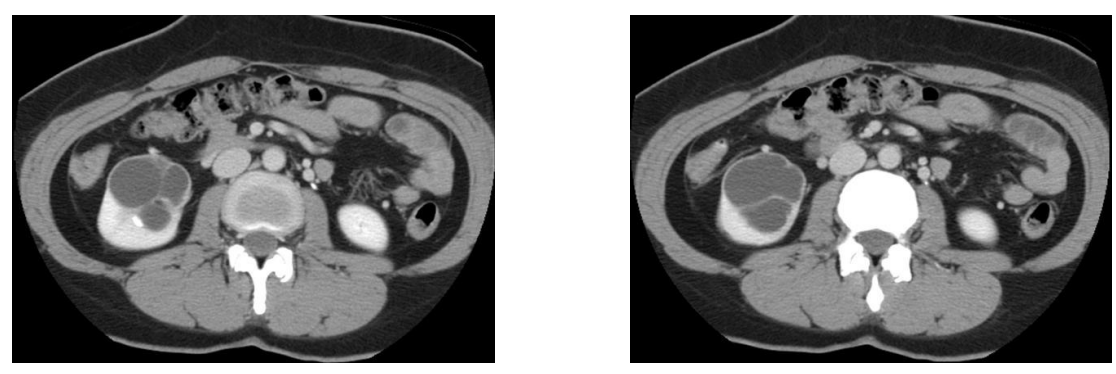

FIGURE 1A and B. Contrast CT images demonstrating a $4.5-\times 4.5-\mathrm{cm}$ cystic mass with multiple internal enhancing septations at the inferior pole of the right kidney. Contrast is visible in the collecting system in Fig. 1A.

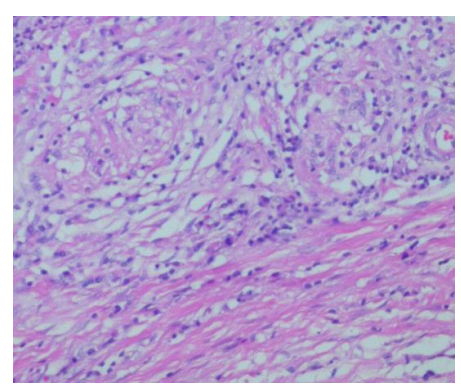

FIGURE 2. Nephrectomy specimen showing chronic interstitial nephritis. Hematoxylin-eosin stain, original magnification $\times 100$.

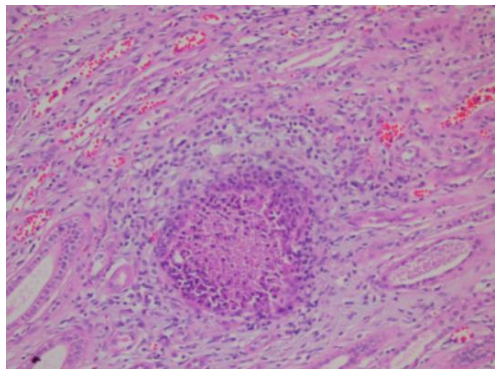

FIGURE 3. Caseating granulomatous renal tuberculosis. Epithelioid cells surround a central area of necrosis that appears irregular, amorphous, and pink. Hematoxylin-eosin stain, original magnification $\times 100$.

\section{Jennifer L. Gurski* and Karen C. Baker}

Department of Surgery, Urology Service, Madigan Army Medical Center, Tacoma, WA

E-mail: Jennifer.gurski@amedd.army.mil, Karen.c.baker@us.army.mil

Received November 26, 2008; Revised December 9, 2008; Accepted December 16, 2008; Published December 25, 2008

KEYWORDS: tuberculosis, extrapulmonary, diagnosis, imaging 
A 44-year-old Philippine woman with a history of positive purified protein derivative (PPD) was referred for hydronephrosis that had been discovered on an ultrasound performed for a single, fleeting episode of right-sided flank pain. The CT scan demonstrated a well-circumscribed cystic mass with enhancing septations at the inferior pole of the right kidney (Fig. 1). The differential diagnosis included xanthogranulomatous pyelonephritis and abscess, although both were thought to be unlikely in the absence of a suggestive history or signs of infection. Given the patient's age and radiographic enhancement, the lesion appeared concerning for multiloculated cystic nephroma vs. cystic renal cell carcinoma. After counseling her as to her options, she underwent right laparoscopic nephrectomy. The pathologic examination revealed caseating, granulomatous, interstitial nephritis (Figs. 2 and 3). Acid-fast organisms were present on the AFB stain.

This case represents an unusual radiographic appearance of renal tuberculosis (TB). Genitourinary TB is the second most common form of extrapulmonary TB after peripheral lymphadenopathy[1]. The manifestations of renal TB include hematuria, sterile pyuria, colic, and renal failure. Constitutional symptoms, such as fever, weight loss, and fatigue, are less common. Patients may be asymptomatic; however, those with renal TB will usually have evidence of concomitant inactive pulmonary disease.

Radiographic findings of early renal TB often are nonspecific and of limited diagnostic value. The calyces may have a "moth eaten" appearance secondary to papillary necrosis. In the later stages of TB, ureteral and infundibular strictures, "beading" hydronephrosis, cavitation, and focal calcification may be present[2]. A small, calcified, nonfunctioning renal unit (the so-called "putty kidney") representing autonephrectomy may be visualized[3].

Renal TB should be included in the differential diagnosis of renal lesions in patients with the appropriate exposure and/or travel history, or who are PPD positive.

\section{REFERENCES}

1. Wise, G.J. and Marella, V.K. (2003) Genitourinary manifestations of tuberculosis. Urol. Clin. North Am. 30, 111121.

2. Mandell, G.L., Douglas, R.G., Bennett, J.E., and Dolin, R. (2005) Mandell, Douglas, and Bennett's Principles and Practice of Infectious Diseases. Elsevier Churchill Livingstone, Philadelphia.

3. Kocakoc, E., Bhatt, S., and Dogra, V.S. (2005) Renal multidector row CT. Radiol. Clin. North Am. 43, $1021-1047$.

\section{This article should be cited as follows:}

Gurski, J.L. and Baker, K.C. (2008) An unusual presentation: renal tuberculosis. TheScientificWorldJOURNAL 8, 1254-1255. DOI 10.1100/tsw.2008.162. 


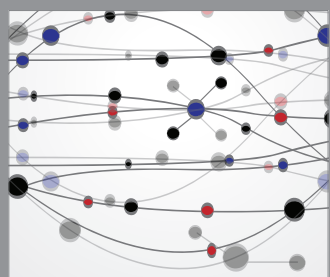

The Scientific World Journal
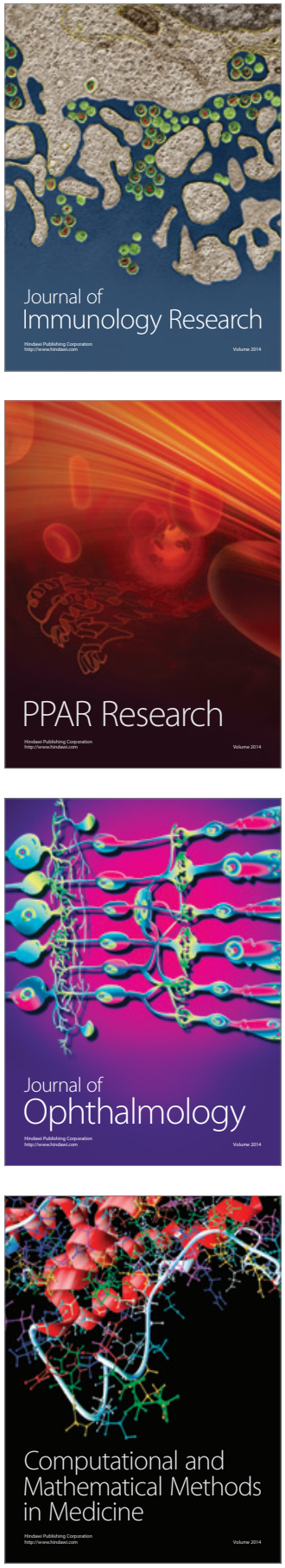

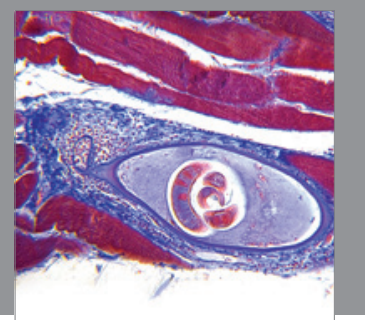

Gastroenterology

Research and Practice
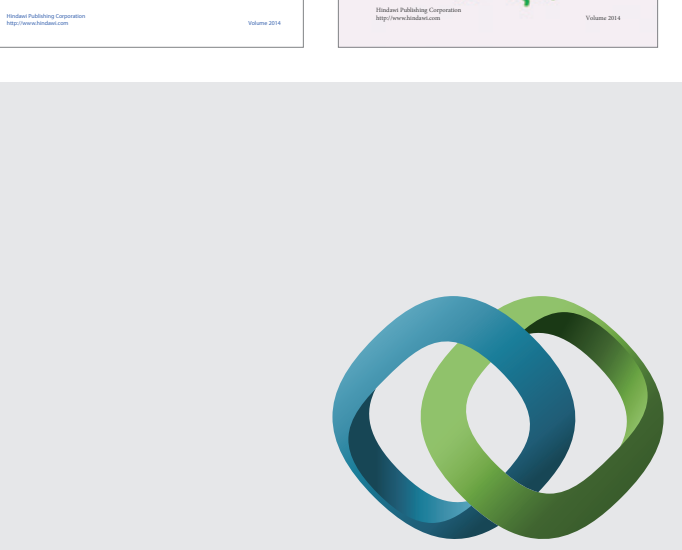

\section{Hindawi}

Submit your manuscripts at

http://www.hindawi.com
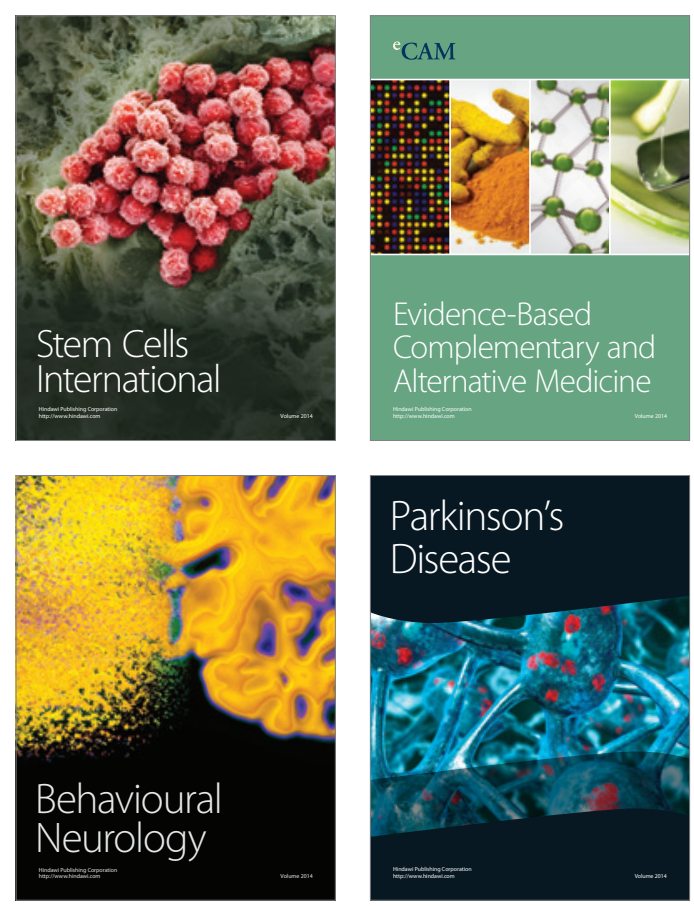

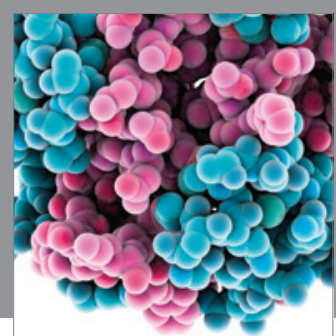

Journal of
Diabetes Research

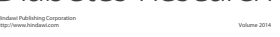

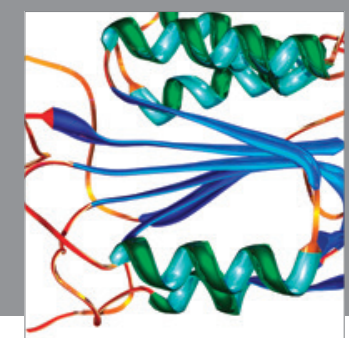

Disease Markers
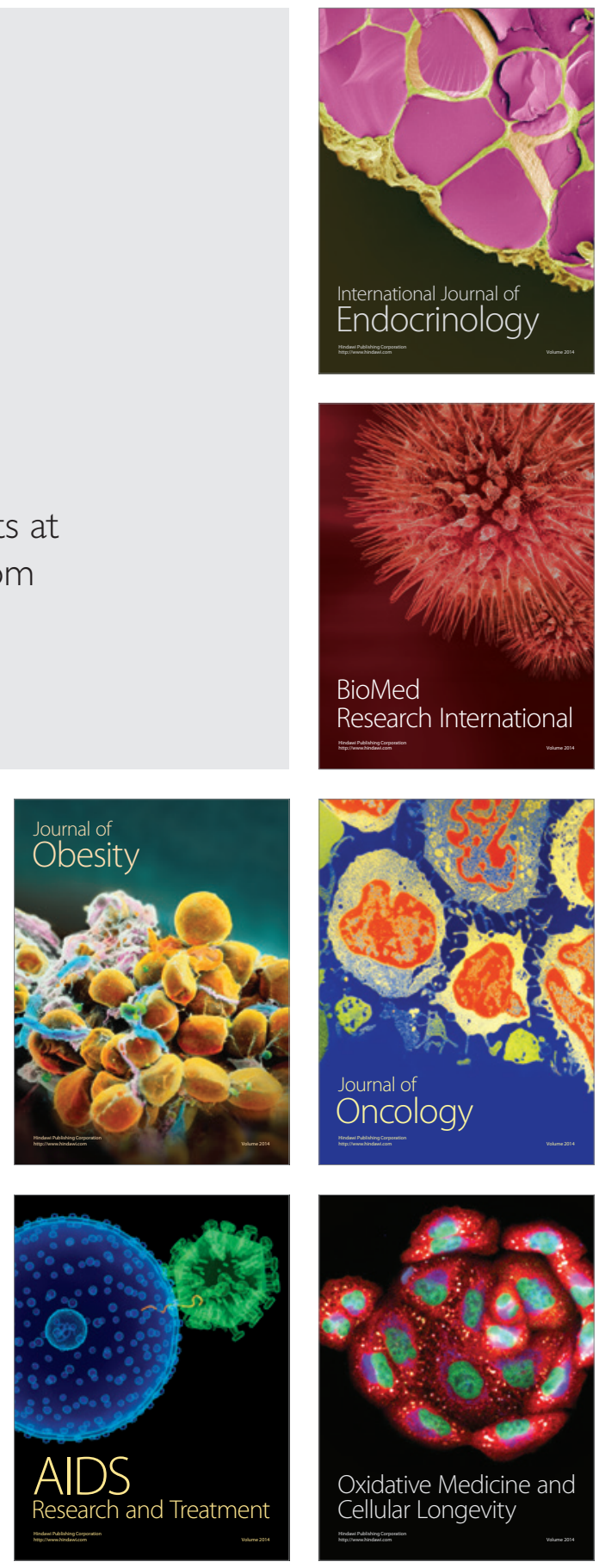